\title{
The effects of dialysis modalities on the progression of coronary artery calcification in dialysis patients
}

\author{
Qingyu Niu ${ }^{\dagger}$, Huiping Zhao $^{\dagger}$, Li Zuo, Mei Wang and Liangying Gan ${ }^{*}$ (I)
}

\begin{abstract}
Background: Hemodialysis (HD) tend to have more hemodynamic changes than peritoneal dialysis (PD), which aggravates inflammation and oxidative stress. Whether HD and PD have different effects on the progression of vascular calcification? Therefore, we produced a study to explore the relationship of dialysis modalities and coronary artery calcification (CAC) progression.

Methods: This was a prospective cohort study. CT scans were performed at enrollment and 2 years later for each patient. Demographic and clinical data were collected. Tobit regression was used to compare delta CAC score between HD and PD patients.

Results: (1) 155 patients were enrolled, including 69 HD and 86 PD patients. (2) The baseline CAC scores were 97 $(1,744)$ in HD and $95(0,324)$ in PD; the follow-up CAC scores were $343(6,1379)$ in HD and $293(18,997)$ in PD. There were no significant differences in baseline, follow-up and delta CAC scores between 2 groups $(P>0.05)$. (3) In Tobit regression, after adjusted for variables, there was no significant difference of CAC progression in HD and PD groups $(P>0.05)$. (4) Logistic regression showed that older age, diabetes and higher time-averaged serum phosphate $(P)$ were associated with faster progression of CAC $(P<0.05)$, but there was no evidence that HD was associated with faster CAC progression compared with PD $(P=0.879)$.

Conclusions: There was no evidence that different dialysis modalities have different effect on CAC progression. Old age, DM and higher time-averaged $\mathrm{P}$ were associated with fast CAC progression.
\end{abstract}

Keywords: Hemodialysis, Peritoneal dialysis, Coronary artery calcification, Vascular calcification

\section{Background}

Cardiovascular death has long been the leading cause of death in chronic kidney disease (CKD) patients [1, 2]. Coronary artery calcification (CAC) is an important factor that increase the risk of cardiovascular disease, which is a common pathological manifestation due to mineral and bone disorder in CKD patients [3-5].

\footnotetext{
* Correspondence: Ganl@bjmu.edu.cn

${ }^{\dagger}$ Qingyu Niu and Huiping Zhao contributed equally to this work. Department of Nephrology, Peking University People's Hospital, 11 Xizhimennan South Street, Xicheng District, Beijing 100044, China
}

When CKD progresses to end stage renal disease (ESRD), kidney replacement therapy is often required. Hemodialysis (HD) and peritoneal dialysis (PD) are the most common dialysis modalities for ESRD patients. There was controversy about the effects of dialysis treatment modalities on the survival of ESRD patients $[6,7]$. Compared with PD, HD may have greater hemodynamic change and hyperdynamic circulation induced by interdialytic fluid accumulation, rapid ultrafiltration and arteriovenous fistula $[8,9]$. These hemodynamic changes may cause vascular endothelial cell dysfunction and initiation of oxidative stress in HD patients. In the study of

(c) The Author(s). 2020 Open Access This article is licensed under a Creative Commons Attribution 4.0 International License, which permits use, sharing, adaptation, distribution and reproduction in any medium or format, as long as you give appropriate credit to the original author(s) and the source, provide a link to the Creative Commons licence, and indicate if changes were made. The images or other third party material in this article are included in the article's Creative Commons licence, unless indicated otherwise in a credit line to the material. If material is not included in the article's Creative Commons licence and your intended use is not permitted by statutory regulation or exceeds the permitted use, you will need to obtain permission directly from the copyright holder. To view a copy of this licence, visit http://creativecommons.org/licenses/by/4.0/ The Creative Commons Public Domain Dedication waiver (http://creativecommons.org/publicdomain/zero/1.0/) applies to the data made available in this article, unless otherwise stated in a credit line to the data. 
Lilien et al., they confirmed that HD procedure induces further endothelial dysfunction in children with ESRD by measuring arterial flow-mediated dilation [10]. Meanwhile, inadequate dialyzer membrane biocompatibility aggravates inflammation and oxidative stress when the artificial materials contact with blood [11]. Oxidative stress and inflammation are also important factors that contribute to vascular calcification [12, 13]. Inversely, PD has little influence on hemodynamics and better preservation of residual renal function, so PD patients may possibly be at a lower cardiovascular risk [14].

However, whether these two dialysis modalities have different effects on the progression of vascular calcification is currently inconclusive. We therefore performed a prospective cohort study of patients with HD and PD to compare the effects of different dialysis modalities on the progression of CAC.

\section{Methods}

\section{Study design and subjects}

This is a prospective cohort study. We enrolled maintenance HD and PD patients with ESRD in our dialysis center from January 2012 to January 2015. Inclusion criteria: (1) age $\geq 18$ years old; (2) dialysis vintage $\geq 3$ months; (3) with stable clinical condition. Exclusion criteria: (1) conditions making CT technically impossible or unreliable (such as severe cardiac arrhythmias); (2) patients who are pregnant or plan to become pregnant within 2 years; (3) patients with acute complications such as heart failure, severe infection, malignant tumor and life expectancy less than 3 months.

\section{Demographic and clinical data}

Baseline demographics were collected, including age, gender, dialysis vintage, primary causes of ESRD, diabetes mellitus (yes or no), body mass index (BMI) and the history of cardiovascular disease (yes or no). Laboratory indices were tested every 3 months during the follow-up period, then calculated the time-averaged values, including serum corrected calcium $(\mathrm{cCa})$, phosphate $(\mathrm{P})$, serum intact parathyroid hormone (iPTH), serum albumin (Alb), serum creatinine (Scr), hemoglobin $(\mathrm{Hb})$, serum triglycerides (TG), low-density lipoprotein cholesterol (LDL-C), high-density lipoprotein cholesterol (HDL-C), total cholesterol (T-Cho) and serum C-reactive protein (CRP). Relative medication use was collected, including calcium-based phosphate binder, non-calucium-based phosphate binder, cinacalcet and vitamin $\mathrm{D}$ analogue.

\section{Evaluation of coronary artery calcification}

CT scans were performed at enrollment and 2-years later in Department of Radiology of our hospital, CAC scores assessed blindly by two radiologists according to the method previously described by Agaston et al. [15]. Delta $(\Delta)$ CAC score was defined as the absolute difference between follow-up CAC score and baseline CAC score, reflecting the progression of CAC during the twoyear follow-up period. To analyze the risk factors of CAC progression, subjects were also classified as $\triangle \mathrm{CAC}$ score $\leq 100$ and $\triangle C A C$ score $>100$.

\section{Statistical methods}

Continuous variables were expressed as mean \pm standard deviation or median with 25 th-75th percentile, and categorical data were expressed as number and percentage. Differences in variables between groups (HD vs. PD; $\triangle C A C$ score $\leq 100$ vs. $>100$ ) were evaluated by using independent sample t-test or the Wilcoxon rank-sum test on the basis of whether the data were normally distributed. Categorical variables of groups were compared using chi-square test. Changes in CAC scores from baseline to the end of followup in each group were compared by paired sample t-test. We compared the differences of $\triangle C A C$ score between two groups by using the Wilcoxon rank-sum test. In the univariate analysis of group $\triangle C A C$ score $\leq 100$ and $>100$, variables with $P<0.100$ were included into multivariate logistic regression model to explore the independent risk factors of CAC progression. Also, important covariates know to be associated with vascular calcification based on clinical insight, such as serum $\mathrm{cCa}, \mathrm{P}$, iPTH were retained in the multivariate logistic regression model.

We evaluated $\triangle \mathrm{CAC}$ score between groups with Tobit regression as it was suitable to analyze variables with floor or ceiling effects as described in previous studies [16]. In our study, there were several patients have no detectable CAC at baseline and still no CAC at the end of 2-year follow up, so $\triangle \mathrm{CAC}$ scores of these patients were 0 . In Tobit regression, we can assume that the endpoint variables $(\Delta$ CAC score) is a normally distributed variable that has been truncated by value of 0 . We made 1 unadjusted model and 4 adjusted models in Tobit regression. The adjusted covariates included in model 1: age, gender; model 2: model 1 variables plus dialysis vintage and diabetes; model 3: model 2 variables plus serum Alb, cCa, P, iPTH, CRP and T-cho; model4: model 3 variables plus noncalcium $\mathrm{P}$ binder and Vitamin $\mathrm{D}$ analogue. $P$ value $<0.05$ was considered to be statistically significant. Tobit regression was performed by STATA software, version14.0, and other statistical analyses were performed using SPSS software, version 22.0. And figures were produced by PRISM software, version 6.0.

\section{Results}

Demographic data and clinical characteristics

We initially enrolled 155 patients, including $69 \mathrm{HD}$ patients and 86 PD patients. All of them were performed CT test at the enrollment. After 2 years, there were 120 
patients (57 in HD, 63 in PD) finished the follow-up CT test. Reasons of elimination including kidney transplantation, transferation, death, motion artefacts or stents of CT scans, and bypass surgery. In HD group, primary causes of ESRD were predominantly chronic glomerulonephritis $(n=38,55.1 \%)$, followed by diabetic nephropathy $(n=14, \quad 20.2 \%)$, chronic tubulointerstitial nephropathy $(n=6,8.7 \%)$, hypertensive nephropathy $(n=4,5.8 \%)$, and others $(n=7,10.1 \%)$; in PD group, there were chronic glomerulonephritis $(n=40,46.5 \%)$, diabetic nephropathy $(n=22,25.6 \%)$, hypertensive nephropathy $(n=12,14.0 \%)$, chronic tubulointerstitial nephropathy $(n=8,9.3 \%)$, and others $(\mathrm{n}=4,4.7 \%)$ (Table 1).

In baseline, the mean age of HD group was $52.1 \pm 13.3$ years, $68.1 \%$ were male, median dialysis vintage was 38 $(12,75)$ months and $24.6 \%$ had diabetes mellitus (DM); and in PD group, the mean age was $54.2 \pm 11.7$ years, $45.4 \%$ were male, median dialysis vintage was 26 (12.8, 58.0) months and $41.9 \%$ had DM. Compared with HD patients, patients in PD group have higher proportions of female and DM, higher levels of time-averaged serum LDL-C, HDL-C and T-Cho, and lower levels of timeaveraged serum Alb (Table 1).

\section{Coronary artery calcification}

The median of baseline CAC score in HD group was 97 $(1744)$, and $95(0,324)$ in PD group (Table 1). There was no significant difference $(P=0.361)$ in the baseline CAC score between 2 groups. Compared with baseline, CAC score of each group showed significant progress after 2year follow-up (Table 2). But between the 2 groups, there was no significant difference in $\triangle C A C$ score: the median $\triangle C A C$ score in HD group was $119(0,389)$, and $136(1,377)$ in PD group $(P=0.766)$ (Table 2). In Fig. 1 , we stratified patients by dialysis modality, and depicted the baseline CAC score and the progression trend of each patient as individual trajectories of CAC scores. And we compared $\triangle \mathrm{CAC}$ scores between $\mathrm{HD}$ and $\mathrm{PD}$ patients in Fig. 2.

In Tobit regression, CAC score progressed with 92.17 per year in HD patients (95\% CI: -16.01 to 200.37 ) and with 126.80 per year in PD patients (95\% CI: 28.54 to 225.07). In unadjusted model of Tobit regression, HD was not significantly associated with higher CAC progression comparing with PD (unadjusted difference:32.73 per year; $95 \% \mathrm{CI}$ : -174.9 to $109.4 ; P=0.649$ ). We performed 4 adjusted models in this part. When fully adjusted for age, gender, dialysis vintage, DM, Alb, cCa, P, $\mathrm{iPTH}, \mathrm{CRP}$ and T-Cho, HD was also not significantly associated with faster progression of CAC than PD (adjusted difference: -130.2 per year; $95 \% \mathrm{CI}:-308.0$ to 47.5; $P=0.148$ ) (Table 3 ).

\section{Subgroup analysis}

Supplementary Table 1 summarized results of subgroup analyses for different conditions of CAC progression in $\mathrm{HD}$ and PD patients. CAC progressed significantly faster in patients with DM than in patients without DM, which can be seen in both HD and PD groups (in HD group, $\triangle C A C$ scores of patients with DM and without DM were $415(198,931)$ and $24(0,292)$ respectively, $P=$ 0.004; in PD group, these were $280(118,734)$ and $25(0$, 278 ), respectively, $P=0.006$;). But no significant difference of CAC progression between HD and PD groups $(P>0.05)$. For patients with dialysis vintage $\leq 60$ or $>60$ months, there weren't significant differences of CAC progression in both HD and PD patients (Supplement Table $1, P>0.05$ ). For HD group, older patients (age $>$ $55)$ tend to has faster progression of CAC than younger patients $(\triangle C A C$ scores in older patients were $172(0$, $474)$ and $51(0,347)$ in younger patients, $P=0.040)$. However, the different speeds of calcification progression in different age groups weren't seen in PD patients, and there also no significant different between HD and PD groups $(\mathrm{P}>0.05)$.

\section{Influencing factors of CAC progression}

To explore the factors that influence the progression of CAC, we devided patients into 2 gourps: fast progression of CAC $(\triangle C A C$ score $>100)$ and slow progression of $C A C(\triangle C A C$ score $\leq 100)$. Compared with the slow progression group, patients with fast CAC progression exhibited older age, higher proportion of DM and use of calcium-based phosphate binder, higher BMI, timeaveraged CRP $(P<0.05$; Supplemental Table 2$)$. In Logistic regression, after adjusted for confounders, the result showed that older age, DM and higher time-averaged serum $\mathrm{P}$ were independent risk factors of fast CAC progression $(\mathrm{P}<0.05$; Table 4$)$, but no evidence shown that dialysis modality was associated with faster CAC progression $(\mathrm{OR}=1.097,95 \% \mathrm{CI}: \quad 0.331-3.634, \quad P=0.879$, Table 4).

\section{Discussion}

Our study indicated whether dialysis modalities affect the progression of coronary calcification. In this prospective cohort, we enrolled $69 \mathrm{HD}$ patients and $86 \mathrm{PD}$ patients. After 2-year follow-up period, we didn't find the significant differences of CAC progression between HD and PD groups. And in our study, older age, DM and higher time-averaged serum $\mathrm{P}$ were associated with faster CAC progression.

There were few studies have investigated the relationship of dialysis modality and the progression of vascular calcification. In Lee's study [17], they included 15 PD patients and $18 \mathrm{HD}$ patients who were tested for CAC scores at 1, 6 and 12 months. They didn't find 
Table 1 Characteristics of patients on hemodialysis or peritoneal dialysis

\begin{tabular}{|c|c|c|c|}
\hline & $\mathrm{HD}(n=69)$ & $\mathrm{PD}(n=86)$ & $P$ Value \\
\hline Age (years) & $52.1 \pm 13.3$ & $54.2 \pm 11.7$ & 0.306 \\
\hline Dialysis vintage (months) & $38.0(12.0,75.0)$ & $26.0(12.8,58.0)$ & 0.084 \\
\hline Male (n, \%) & $47(68.1)$ & $39(45.4)$ & $0.006^{*}$ \\
\hline $\mathrm{DM}(\mathrm{n}, \%)$ & $17(24.6)$ & $36(41.9)$ & $0.028^{*}$ \\
\hline \multicolumn{4}{|l|}{ Primary causes of ESRD [n (\%)] } \\
\hline CGN & $38(55.1)$ & $40(46.5)$ & 0.289 \\
\hline DN & $14(20.3)$ & $22(25.6)$ & 0.438 \\
\hline CTIN & $6(8.7)$ & $8(9.3)$ & 0.896 \\
\hline $\mathrm{HN}$ & $4(5.8)$ & $12(14.0)$ & 0.107 \\
\hline Others & $7(10.1)$ & $4(4.6)$ & 0.294 \\
\hline CVD in history, n (\%) & $19(27.5)$ & $21(24.4)$ & 0.621 \\
\hline BMI $\left(\mathrm{Kg} / \mathrm{m}^{2}\right)$ & $22.64 \pm 3.65$ & $23.06 \pm 3.60$ & 0.476 \\
\hline \multicolumn{4}{|l|}{ Time-averaged test value } \\
\hline $\mathrm{Hb}(\mathrm{g} / \mathrm{L})$ & $114.5(111.0,116.4)$ & $115.6(110.9117 .3)$ & 0.345 \\
\hline Alb (g/L) & $40.1 \pm 2.3$ & $38.3 \pm 2.9$ & $<0.001^{*}$ \\
\hline $\mathrm{cCa}(\mathrm{mmol} / \mathrm{L})$ & $2.31 \pm 0.34$ & $2.38 \pm 0.11$ & 0.114 \\
\hline $\mathrm{P}(\mathrm{mmol} / \mathrm{L})$ & $1.66 \pm 0.37$ & $1.56 \pm 0.62$ & 0.335 \\
\hline iPTH (pg/ml) & $170.6(81.8363 .2)$ & $187.9(107.8340 .8)$ & 0.615 \\
\hline Scr (umol/L) & $1043 \pm 227$ & $960 \pm 273$ & 0.078 \\
\hline CRP (mg/L) & $3.16(1.53,6.33)$ & $2.44(1.54,4.53)$ & 0.669 \\
\hline LDL-C (mmol/L) & $2.13 \pm 0.58$ & $2.97 \pm 0.74$ & $<0.001^{*}$ \\
\hline $\mathrm{HDL}-\mathrm{C}(\mathrm{mmol} / \mathrm{L})$ & $0.92(0.85,1.09)$ & $1.06(0.93,1.28)$ & $0.006^{*}$ \\
\hline T-Cho (mmol/L) & $4.24 \pm 0.81$ & $5.17 \pm 0.96$ & $<0.001^{*}$ \\
\hline CRP (mg/L) & $3.16(1.53,6.33)$ & $2.44(1.54,4.53)$ & 0.669 \\
\hline \multicolumn{4}{|l|}{ Medication use } \\
\hline Calcium-based P binder ${ }^{\mathrm{a}}(\mathrm{n}, \%)$ & $56(100.0)$ & $56(88.9)$ & $0.029^{*}$ \\
\hline Non-calcium-based P binder ${ }^{b}(n, \%)$ & $3(5.3)$ & $12(19.1)$ & $0.023^{*}$ \\
\hline Cinacalcet $(n, \%)$ & $2(3.5)$ & $1(1.6)$ & 0.918 \\
\hline Vitamin D analogue (n, \%) & $29(50.9)$ & $15(23.8)$ & $0.002^{*}$ \\
\hline Baseline CAC Score & 97 (1744) & $95(0,324)$ & 0.361 \\
\hline
\end{tabular}

${ }^{*} P<0.05$ Notes: CGN: chronic glomerulonephritis; DN: diabetic nephropathy; CTIN: chronic tubulointerstitial nephropathy; HN: hypertensive nephropathy; BMI: body mass index; Hb: hemoglobin; Alb: albumin; cCa: corrected calcium; P: phosphate; iPTH: Intact Parathyroid Hormone; ALP: alkaline phosphatase; $\mathrm{CO}_{2} \mathrm{CP}$ : carbon dioxide combining power; Scr: serum creatinine; UA: uric acid; TG: triglyceride; LDL-C: low density lipoprotein cholesterol; HDL-C: high density lipoprotein cholesterol; T-Cho: total cholesterol; a, calcium carbonate; b, lanthanum carbonate or sevelamer

Table 2 Baseline and follow-up CAC scores and delta CAC scores of the two groups

\begin{tabular}{|c|c|c|c|c|c|c|}
\hline & \multicolumn{2}{|l|}{$\mathrm{HD}$} & \multirow[t]{2}{*}{$P$} & \multicolumn{2}{|l|}{ PD } & \multirow[t]{2}{*}{$P$} \\
\hline & Baseline $(n=69)$ & Month $24(n=57)$ & & Baseline $(n=86)$ & Month $24(n=63)$ & \\
\hline $\begin{array}{l}\text { CAC score } \\
(\text { mean } \pm \text { SD) }\end{array}$ & $538 \pm 836$ & $870 \pm 1228$ & $<0.001^{*}$ & $335 \pm 699$ & $698 \pm 1174$ & $<0.001^{*}$ \\
\hline $\begin{array}{l}\text { CAC score } \\
\text { median (25th,75th) }\end{array}$ & 97 (1744) & 343 (61379) & $<0.001^{*}$ & $95(0,324)$ & $293(18,997)$ & $<0.001^{*}$ \\
\hline $\begin{array}{l}\triangle C A C \text { score } \\
(\text { mean } \pm S D)\end{array}$ & $332 \pm 615$ & & & $363 \pm 633$ & & 0.788 \\
\hline $\begin{array}{l}\triangle C A C \text { score } \\
\text { median (25th, 75th) }\end{array}$ & $119(0,389)$ & & & $136(1,377)$ & & 0.766 \\
\hline
\end{tabular}

Note: ${ }^{*} P<0.05$ 


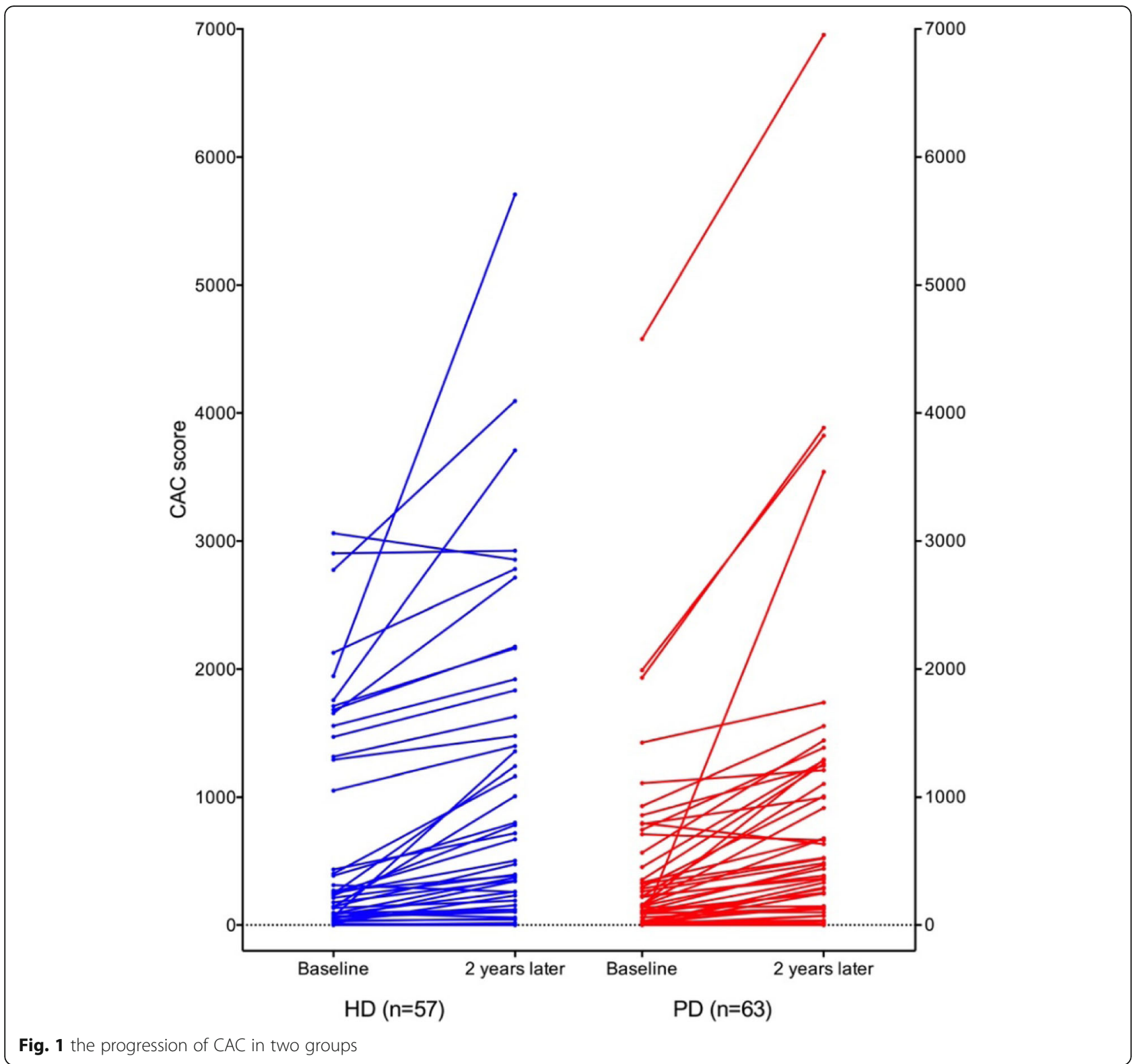

differences in CAC score between HD and PD patients. In the study of Jansz et al. [18], they enrolled 94 HD patients and $40 \mathrm{PD}$ patients at baseline, but only $34 \mathrm{HD}$ patients and 23 PD patients finished the 3-year followup period. Their results shown that patients on PD do not have less CAC progression than patients on HD. However, the sample size of these studies was small.

According to literatures, it was reasonable if we confirm a hypothesis that PD patients have less progression of vascular calcification than HD patients, but our results were negative. There were several reasons that we got these negative results. First, in our dialysis center, the proportion of diabetes in PD patients was significantly higher than that in HD patients, which contribute a lot to the occurrence and progression of vascular calcification. Second, it can be seen from the clinical and laboratory data that the nutritional status of PD patients was worse than that of HD patients (such as serum Alb). Then, the disorders of lipid metabolism in PD patients was more severe. In other words, the overall condition of our PD patients was worse than that of HD patients. Therefore, it was expected that the prevalence of CAC is higher, and the progression is faster in our PD patients comparing to HD group. However, our results did not show a faster progression of CAC in the PD group.

We also analysed the independent risk factors of fast CAC progression by using logistic regression model. After adjusted for covariates, the result showed that older age, DM, higher time-averaged serum $\mathrm{P}$ were independent risk factors of fast $\mathrm{CAC}$ progression. Aging and 


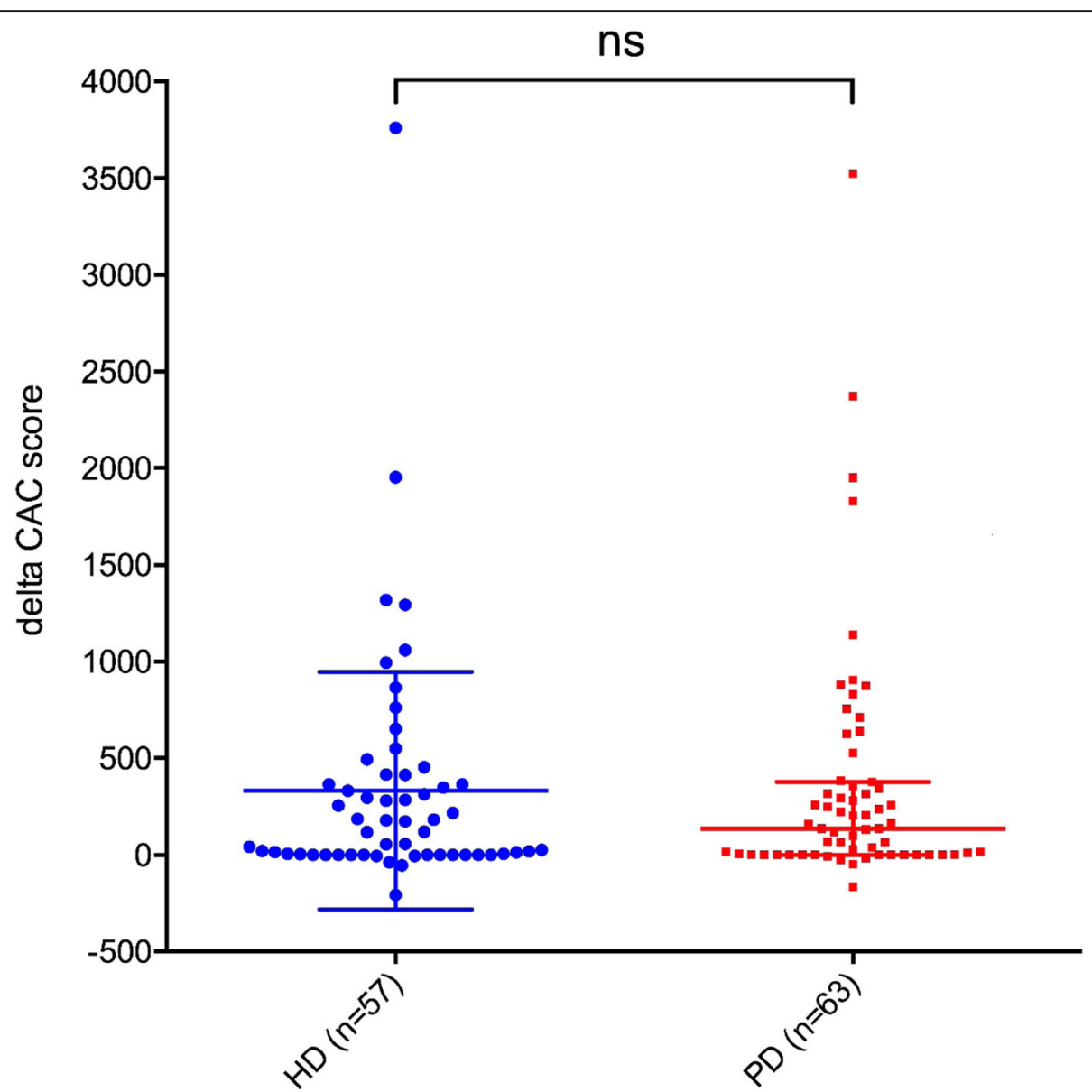

Fig. 2 the delta CAC scores in two groups. (notes: Each point represented the increased value in coronary artery calcification scores during 2-year follow-up period of a patient)

diabetes are recognized risk factors for the occurrence and progression of vascular calcification, and this was reported by many studies before [19-21]. Meanwhile, among various risk factors of vascular calcification in CKD patients, hyperphosphatemia is most strongly involved with calcification and a main part of CKD-MBD [22]. Many clinical researches have investigated that

Table 3 Effect estimates of CAC progression for PD compared with $\mathrm{HD}$ assessed by Tobit regression

\begin{tabular}{llll}
\hline$\triangle$ CAC score (per year) & Coefficient & $95 \%$ Cl & P \\
\hline Unadjusted model (PD as ref.) & -32.7 & -174.9 to 109.4 & 0.649 \\
Adjusted model 1 (PD as ref.) & -59.4 & -202.6 to 83.8 & 0.413 \\
Adjusted model 2 (PD as ref.) & -44.7 & -184.0 to 94.6 & 0.526 \\
Adjusted model 3 (PD as ref.) & -112.3 & -285.7 to 61.2 & 0.201 \\
Adjusted model 4 (PD as ref.) & -130.2 & -308.0 to 47.5 & 0.148
\end{tabular}

Notes:

Adjusted model 1: adjusted for age and gender;

Adjusted model 2: adjusted model $1+$ dialysis vintage and diabetes mellitus;

Adjusted model 3: adjusted model $2+$ Alb, Ca, P, iPTH, CRP, T-Cho;

Adjusted model 4: adjusted model $3+$ non-calcium $\mathrm{P}$ binder, Vitamin

$D$ analogue hyperphosphatemia is nearly associated with advanced vascular calcification [22-25]. And in vitro studies, highphosphorus medium can calcify vascular smooth muscle cells [26]; in vivo studies, Pi loading can promote vascular calcification in uremic rodents [27]. However, in our study, we didn't find the relationship between serum $\mathrm{Ca}$ and $\mathrm{iPTH}$ levels and progression of CAC. The possible reason may be that our center has strictly adhered to continuous quality improvement for $\mathrm{Ca}$ and $\mathrm{P}$ metabolic disorders, so laboratory data of most patients were within the optimal range, which minimizes the risk of complications and mortality in patients [28].

There were several strengths of our study. First, till now, our study was the largest to compare the progression of vascular calcification between different dialysis modalities. Second, among patients we included, the rate of loss of follow-up was relatively low, ensuring the stability of the results. Third, we chose the tobit regression to analysis the different of $\triangle C A C$ score between HD and PD patients. The Tobit model, also called a censored regression model, is designed to estimate linear 
Table 4 Influencing factors of fast CAC progression in logistic regression model

\begin{tabular}{lllll}
\hline Variables & B & OR & $95 \% \mathrm{Cl}$ & P \\
\hline Age (/per year) & 0.045 & 1.046 & $1.000-1.095$ & $0.049^{*}$ \\
DM (yes vs. no) & 1.394 & 7.714 & $2.095-28.402$ & $0.002^{*}$ \\
BMI (/per 1 Kg/m²) & 0.121 & 1.129 & $0.946-1.347$ & 0.179 \\
Dialysis modalities (HD vs. PD) & 0.093 & 1.097 & $0.331-3.634$ & 0.879 \\
Time-averaged Ca (/per 1 mmol/L) & -2.683 & 0.068 & $0.001-5.348$ & 0.228 \\
Time-averaged P (/per 1 mmol/L) & 2.574 & 17.147 & $2.863-102.709$ & $0.002^{*}$ \\
Time-averaged iPTH (/per 1 mmol/L) & 0.001 & 1.001 & $0.998-1.004$ & 0.652 \\
Time-averaged CRP (/per 1 mmol/L) & 0.056 & 1.057 & $0.929-1.203$ & 0.397 \\
\hline
\end{tabular}

Note: ${ }^{*} P<0.05$

relationships between variables when there is either leftor right-censoring in the dependent variable, which has been used in many areas of medical science [29, 30]. However, there were also some limitations. First, there were differences in the clinical situation of patients between HD and PD groups, which may affect the effect of comparison. Meanwhile, the follow-up period wasn't long enough. Since vascular calcification progresses slowly, it may take longer to detect changes.

\section{Conclusions}

In summary, we did'n find the significant different effects between HD and PD on CAC progression. This indicated that PD may not associated with less vascular calcification progression. This result may provide some clinical evidence for choosing the appropriate dialysis modalities. And in our study, older age, DM, higer timeaveraged serum $\mathrm{P}$ were associated withfast CAC progression. Large sample size and high-quality clinical research is still needed in the future to explore the effects of different dialysis modalities on vascular calcification.

\section{Supplementary information}

Supplementary information accompanies this paper at https://doi.org/10. 1186/s12882-020-01963-x.

\section{Additional file 1}

\section{Abbreviations}

CKD: chronic kidney disease; ESRD: end stage renal disease;

CVD: cardiovascular disease; CAC: coronary artery calcification; HD: hemodialysis; PD: peritoneal dialysis; CT: computed tomography; BMl: body mass index; cCa: corrected calcium; P: phosphate; iPTH: serum intact parathyroid hormone; ALB: albumin; TG: triglycerides; LDL-C: Iowdensity lipoprotein cholesterol; HDL-C: high-density lipoprotein cholesterol; T-Cho: total cholesterol; Scr: serum creatinine; Hgb: hemoglobin

\section{Acknowledgements}

None.

\section{Authors' contributions}

(1) Design of the work; or the acquisition, analysis, or interpretation of data for the work: QN, HZ, LG; (2) Data collection: QN, HZ; (3) Drafting the work or revising it critically for important intellectual content: QN; LZ, MW; (4) Final approval of the version to be published: LG; (5) Agreement to be accountable for all aspects of the work in ensuring that questions: LG. The author(s) read and approved the final manuscript.

\section{Funding}

Gan Liangying has received grants from Capital Clinical Characteristics Application Program (No Z131107002213122); Niu Qingyu has recived grants from Peking University Health Science Center Outstanding Doctoral Student Innovation Fund (No number).

\section{Availability of data and materials}

The data used of this study are available from the corresponding author on reasonable request.

Ethics approval and consent to participate

This study was approved by the Ethics Committee of Peking University Health Science Center (IRB00001052-11055). And all participants signed informed consents.

\section{Consent for publication}

Not applicable.

\section{Competing interests}

All authors have no conflicts of interest related to this study.

Received: 20 February 2020 Accepted: 17 July 2020

Published online: 25 July 2020

\section{References}

1. Chen J, Budoff MJ, Reilly MP, Yang W, Rosas SE, Rahman M, Zhang X, Roy $J A$, Lustigova $E$, Nessel $L$, et al. Coronary artery calcification and risk of cardiovascular disease and death among patients with chronic kidney disease. JAMA Cardiol. 2017;2(6):635-43.

2. Niu Q, Hong Y, Lee $\mathrm{CH}$, Men C, Zhao H, Zuo L. Abdominal aortic calcification can predict all-cause mortality and CV events in dialysis patients: a systematic review and meta-analysis. PLoS One. 2018;13(9): e0204526.

3. Budoff MJ, Hokanson JE, Nasir K, Shaw LJ, Kinney GL, Chow D, Demoss D, Nuguri V, Nabavi V, Ratakonda R, et al. Progression of coronary artery calcium predicts all-cause mortality. J Am Coll Cardiol Img. 2010;3(12):1229-

4. London GM, Marchais SJ, Guerin AP, Boutouyrie P, Metivier F, de Vernejoul MC. Association of bone activity, calcium load, aortic stiffness, and calcifications in ESRD. J Am Soc Nephrol. 2008;19(9):1827-35.

5. Garabed E, Norbert L, Bertram LK: Kidney Disease: Improving Global Outcomes (KDIGO) CKD-MBD Update Work Group. KDIGO 2017 Clinical practice guideline update for the diagnosis, evaluation, prevention, and treatment of chronic kidney disease-mineral and bone disorder (CKD-MBD). Kidney International Supplement 2017, 7(1):1-59.

6. Kumar VA, Sidell MA, Jones JP, Vonesh EF. Survival of propensity matched incident peritoneal and hemodialysis patients in a United States health care system. Kidney Int. 2014;86(5):1016-22.

7. Perl J, Wald R, McFarlane P, Bargman JM, Vonesh E, Na Y, Jassal SV, Moist L. Hemodialysis vascular access modifies the association between dialysis modality and survival. J Am Soc Nephrol. 2011;22(6):1113-21. 
8. Kosch M, Levers A, Fobker M, Barenbrock M, Schaefer RM, Rahn KH, Hausberg M. Dialysis filter type determines the acute effect of haemodialysis on endothelial function and oxidative stress. Nephrol Dialysis Transplantation. 2003;18(7):1370-5.

9. Dikow R, Schwenger V, Zeier M, Ritz E. Do AV fistulas contribute to cardiac mortality in hemodialysis patients? Seminars in dialysis. 2002;15(1):14-17.

10. Lilien MR, Koomans HA, Schröder $\mathrm{CH}$. Hemodialysis acutely impairs endothelial function in children. Pediatric Nephrology (Berlin, Germany) 2005, 20(2):200-204.

11. Abe M, Hamano T, Wada A, Nakai S, Masakane I. Effect of dialyzer membrane materials on survival in chronic hemodialysis patients: results from the annual survey of the Japanese Nationwide Dialysis registry. PLoS One. 2017;12(9):e0184424.

12. Rogers MA, Aikawa E. Cardiovascular calcification: artificial intelligence and big data accelerate mechanistic discovery. Nat Rev Cardiol. 2019;16(5):26174.

13. Niu Q, Zhao H, Wu B, Tsai S, Wu J, Zhang M, Lu L, Qiao J, Men C, Zuo L, et al. Study on the prevalence of vascular calcification in different types of arteries and influencing factors in maintenance peritoneal Dialysis patients. Blood Purif. 2019:47 Suppl 1(Suppl 1):8-16.

14. Moist LM, Port FK, Orzol SM, Young EW, Ostbye T, Wolfe RA, HulbertShearon $T$, Jones CA, Bloembergen WE. Predictors of loss of residual renal function among new dialysis patients. J Am Soc Nephrol. 2000; 11(3):556-64.

15. Agatston AS, Janowitz WR, Hildner FJ, Zusmer NR, Viamonte M Jr, Detrano R. Quantification of coronary artery calcium using ultrafast computed tomography. J Am Coll Cardiol. 1990;15(4):827-32.

16. Twisk J, Rijmen F. Longitudinal tobit regression: a new approach to analyze outcome variables with floor or ceiling effects. J Clin Epidemiol. 2009;62(9): 953-8.

17. Lee C-M, Chen P-W, Leung T-K, Wang H-J, Kung C-H, Lin Y-H, Hsiao $\mathrm{W}-\mathrm{T}$, Chen $\mathrm{Y}-\mathrm{Y}$. Comparison of coronary artery calcification in peritoneal and hemodialysis patients. J Experimental Clin Med. 2011; 3(2):89-92.

18. Jansz $\Pi$, Verhaar MC, London $\mathrm{GM}$, van Jaarsveld BC. Is progression of coronary artery calcification influenced by modality of renal replacement therapy? A systematic review. Clin Kidney J. 2018;11(3):353-61.

19. Taniwaki $H$, Ishimura $E$, Tabata $T$, Tsujimoto $Y$, Shioi A, Shoji T, Inaba $M$, Inoue T, Nishizawa Y. Aortic calcification in haemodialysis patients with diabetes mellitus. Nephrol Dialysis Transplantation. 2005;20(11): 2472-8.

20. Verbeke F, Van Biesen W, Honkanen E, Wikström B, Jensen PB, Krzesinski JM, Rasmussen M, Vanholder R, Rensma PL. Prognostic value of aortic stiffness and calcification for cardiovascular events and mortality in dialysis patients: outcome of the calcification outcome in renal disease (CORD) study. Clin Am Soc Nephrol. 2011;6(1):153-9.

21. Al-Aly Z. Medial vascular calcification in diabetes mellitus and chronic kidney disease: the role of inflammation. Cardiovascular Hematological Disorders Drug Targets. 2007;7(1):1-6.

22. Block GA, Klassen PS, Lazarus JM, Ofsthun N, Lowrie EG, Chertow GM. Mineral metabolism, mortality, and morbidity in maintenance hemodialysis. J Am Soc Nephrol. 2004;15(8):2208-18.

23. Yamada S, Giachelli CM. Vascular calcification in CKD-MBD: roles for phosphate, FGF23, and Klotho. Bone. 2017;100:87-93.

24. Shigematsu T, Kono T, Satoh K, Yokoyama K, Yoshida T, Hosoya T, Shirai K. Phosphate overload accelerates vascular calcium deposition in end-stage renal disease patients. Nephrology Dialysis Transplantation 2003, 18 Suppl 3: iii86-89.

25. Adeney KL, Siscovick DS, Ix JH, Seliger SL, Shlipak MG, Jenny NS, Kestenbaum BR. Association of serum phosphate with vascular and valvular calcification in moderate CKD. J Am Soc Nephrol. 2009;20(2):381-7.

26. Giachelli $\mathrm{CM}$. The emerging role of phosphate in vascular calcification. Kidney Int. 2009;75(9):890-7.

27. El-Abbadi MM, Pai AS, Leaf EM, Yang HY, Bartley BA, Quan KK, Ingalls CM, Liao HW, Giachelli CM. Phosphate feeding induces arterial medial calcification in uremic mice: role of serum phosphorus, fibroblast growth factor-23, and osteopontin. Kidney Int. 2009;75(12): 1297-307.

28. Lamina C, Kronenberg F, Stenvinkel P, Froissart M, Forer L, Schönherr S, Wheeler DC, Eckardt KU, Floege J. Association of changes in bone mineral parameters with mortality in haemodialysis patients: insights from the ARO cohort. Nephrol Dialysis Transplantation. 2020;35(3):478-487.

29. Wang L, Zhang Z, McArdle JJ, Salthouse TA. Investigating ceiling effects in ongitudinal data analysis. Multivar Behav Res. 2009;43(3):476-96.

30. Sattar A, Weissfeld LA, Molenberghs G. Analysis of non-ignorable missing and left-censored longitudinal data using a weighted random effects tobit model. Stat Med. 2011;30(27):3167-80.

\section{Publisher's Note}

Springer Nature remains neutral with regard to jurisdictional claims in published maps and institutional affiliations.
Ready to submit your research? Choose BMC and benefit from:

- fast, convenient online submission

- thorough peer review by experienced researchers in your field

- rapid publication on acceptance

- support for research data, including large and complex data types

- gold Open Access which fosters wider collaboration and increased citations

- maximum visibility for your research: over $100 \mathrm{M}$ website views per year

At BMC, research is always in progress.

Learn more biomedcentral.com/submissions 